Indiana DOT Precast Concrete Pavement Forum

Indianapolis, Indiana - August 11, 2016

\title{
PRECAST CONCRETE PAVEMENT PRACTICES OVERVIEW
}

\section{Precast Concrete Pavements}

Rapid/Longer Lasting Pavement Rehabilitation
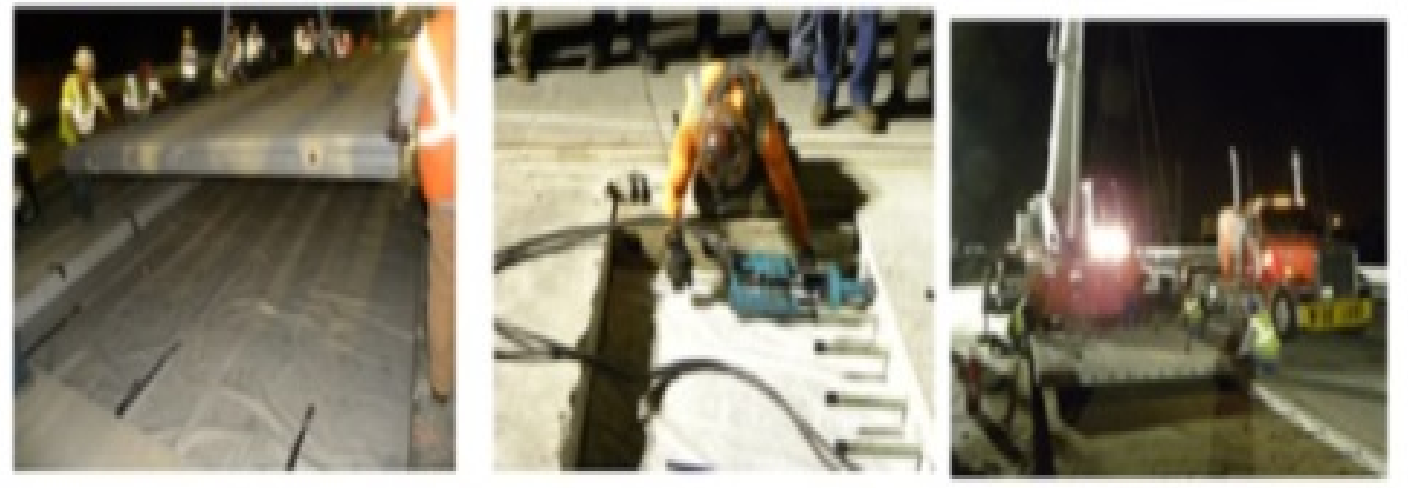

Shiraz Tayabji, stayabji@gmail.com Applied Research Associates, Inc. (ARA)

Ellicott City, MD 


\section{The Need - Pavement Rehab Under Heavy Urban Traffic A very serious issue throughout urban US}

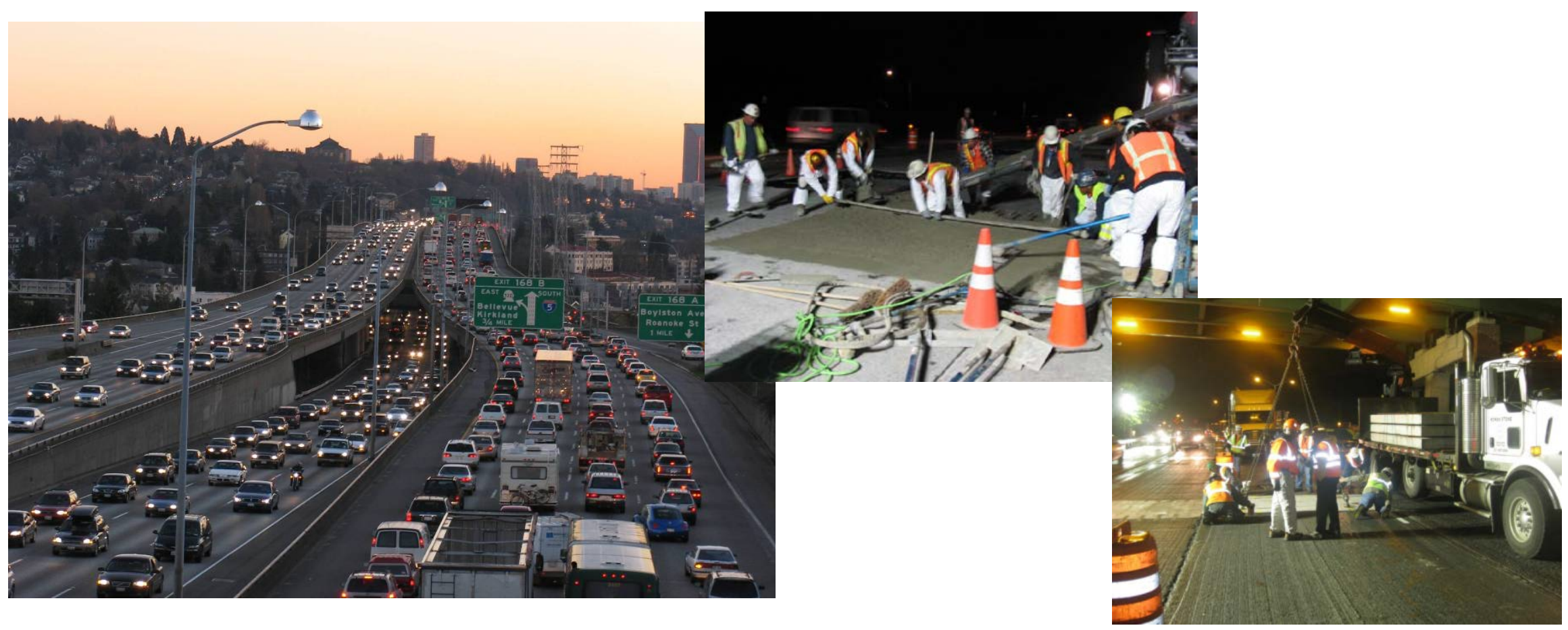

- Shorter closure, but possibly shorter service life (rapid setting concrete)

- Longer service life, but longer closure (conventional concrete paving)

- Shorter closure \& longer service life (PRECAST PAVEMENT) 


\section{Preamble}

$>$ PCP technology is not a passing fad. It is here to stay

$>$ PCP technology is used routinely by several agencies for rapid repair and rehabilitation of concrete as well as asphalt pavements

$>$ PCP projects have been successfully constructed in numerous States by contractors with no prior experience with PCP \& precast panels can be fabricated by most precaster

$>$ Good availability of precast plants throughout the US 


\section{PCP Initiatives in the US}

(Actively undertaken since mid-1990's)

$>$ FHWA (since mid-1990's)

$>$ Highway and airport agencies (since 2001)

$>$ Industry (since 2001)

$>$ AASHTO TIG (mid-2000's)

$>$ SHRP2 Project R05 (2008 - 2012)

$>$ FHWAIAASHTO - SHRP2 Project R05 products implementation program (2013 current)

- Tech Support

- Financial support 


\section{PCP Background}

- PCP is a recent technology - in use since 2001

- Used primarily for RAPID repair \& rehabilitation \& longer-lasting treatments

- Panels fabricated off-site, transported to project site \& installed on a prepared foundation

- Only minimal field curing time required

- Typically, night-time work \& short work windows

- Typically, repair/rehab along a single lane

- Multiple-lane repair/rehab possible based on site constraints
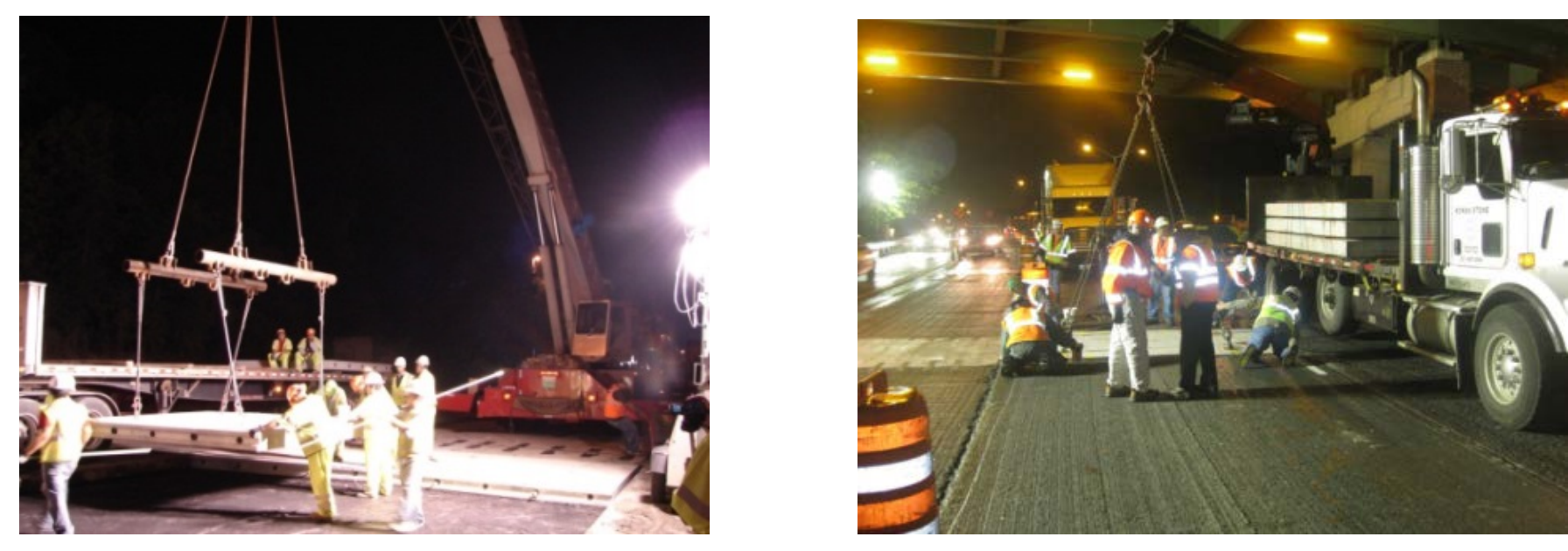


\section{Traffic Considerations}

$>$ Traffic volume - is it heavy enough to preclude other pavement alternatives?

- If fast-track fixed-form or slipform paving techniques are possible, use of precast pavement may not be the best option!

$>$ Alternate routes

- If traffic can be staged or detoured, use of precast pavement may not be the best option!

But, if there is only 8 hours or less of lane closures to perform the repair/rehab work, precast pavement should be strongly considered 


\section{PCP Systems}

$>$ For intermittent repairs

- Nominally reinforced panels

- Prestressed panels

$>$ For continuous applications

- Jointed PCP systems (JPrCP)

o Nominally reinforced panels

- Prestressed panels

- Post-tensioned systems (PPCP) - fewer active joints; longer sections

Generic \& Proprietary Systems (Components) Available
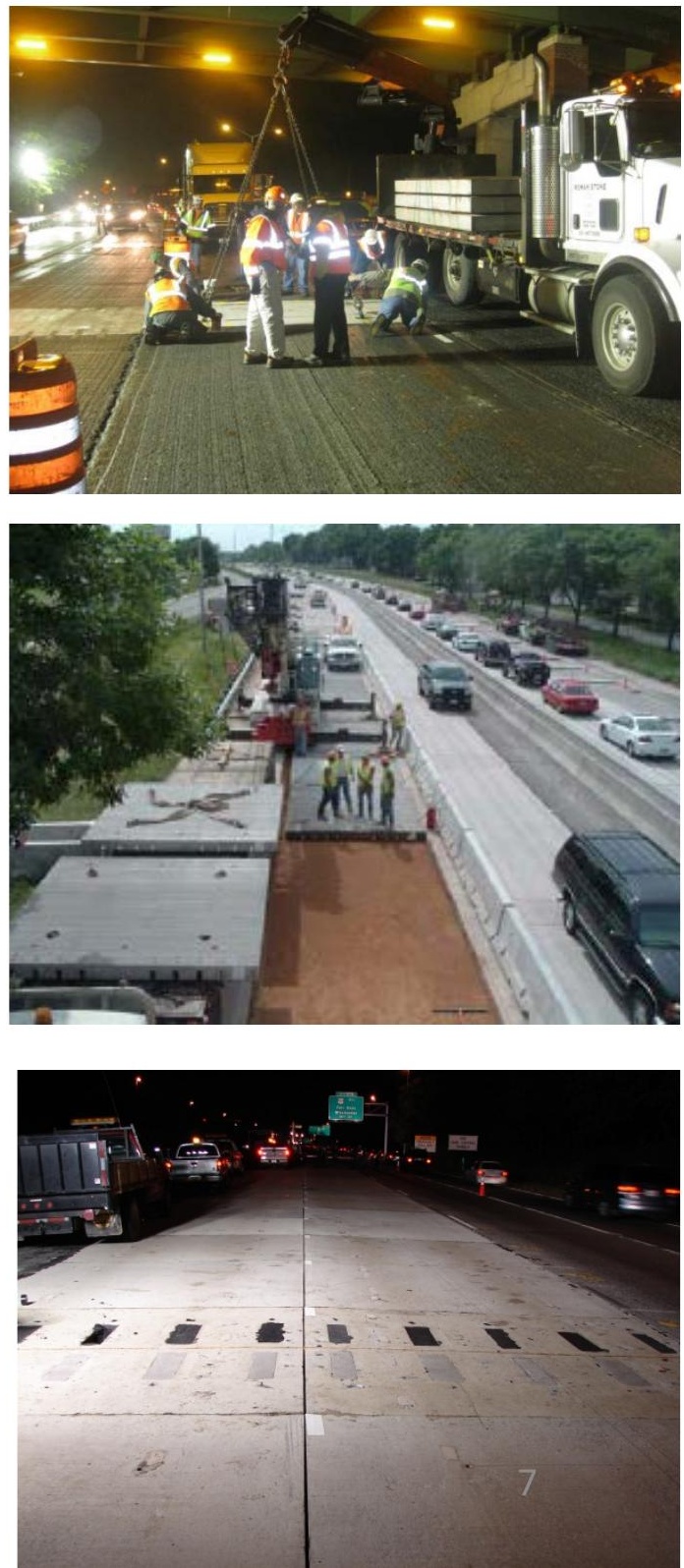


\section{PCP Systems}
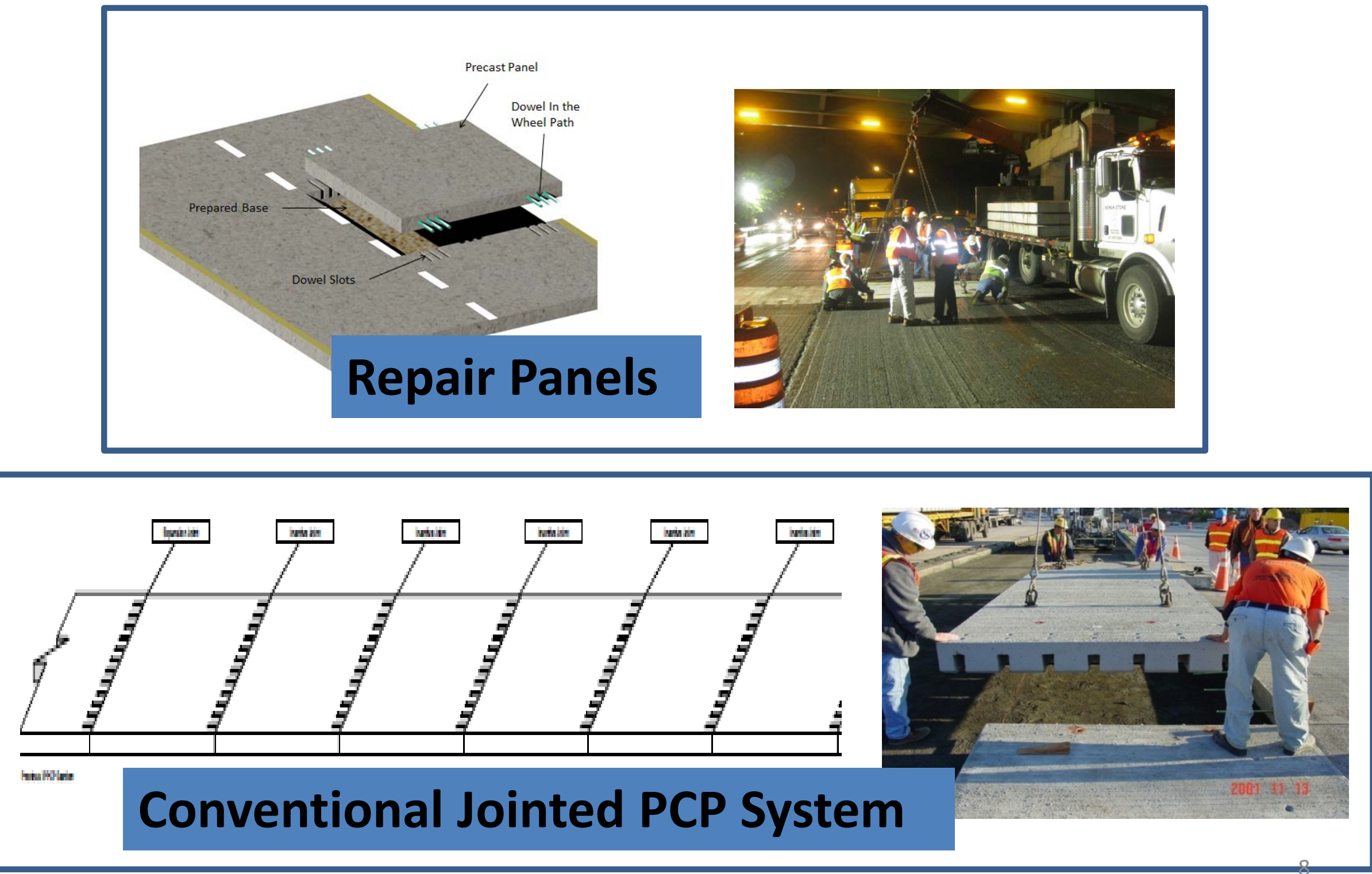


\section{PCP Used by US Highway Agencies 2001 through 2015}

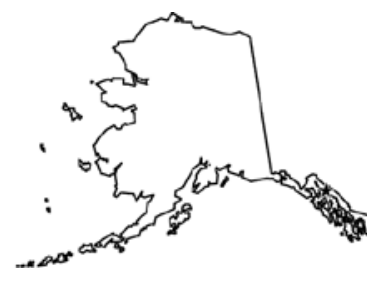

$\therefore$

20 PCP constructed 2001-2015

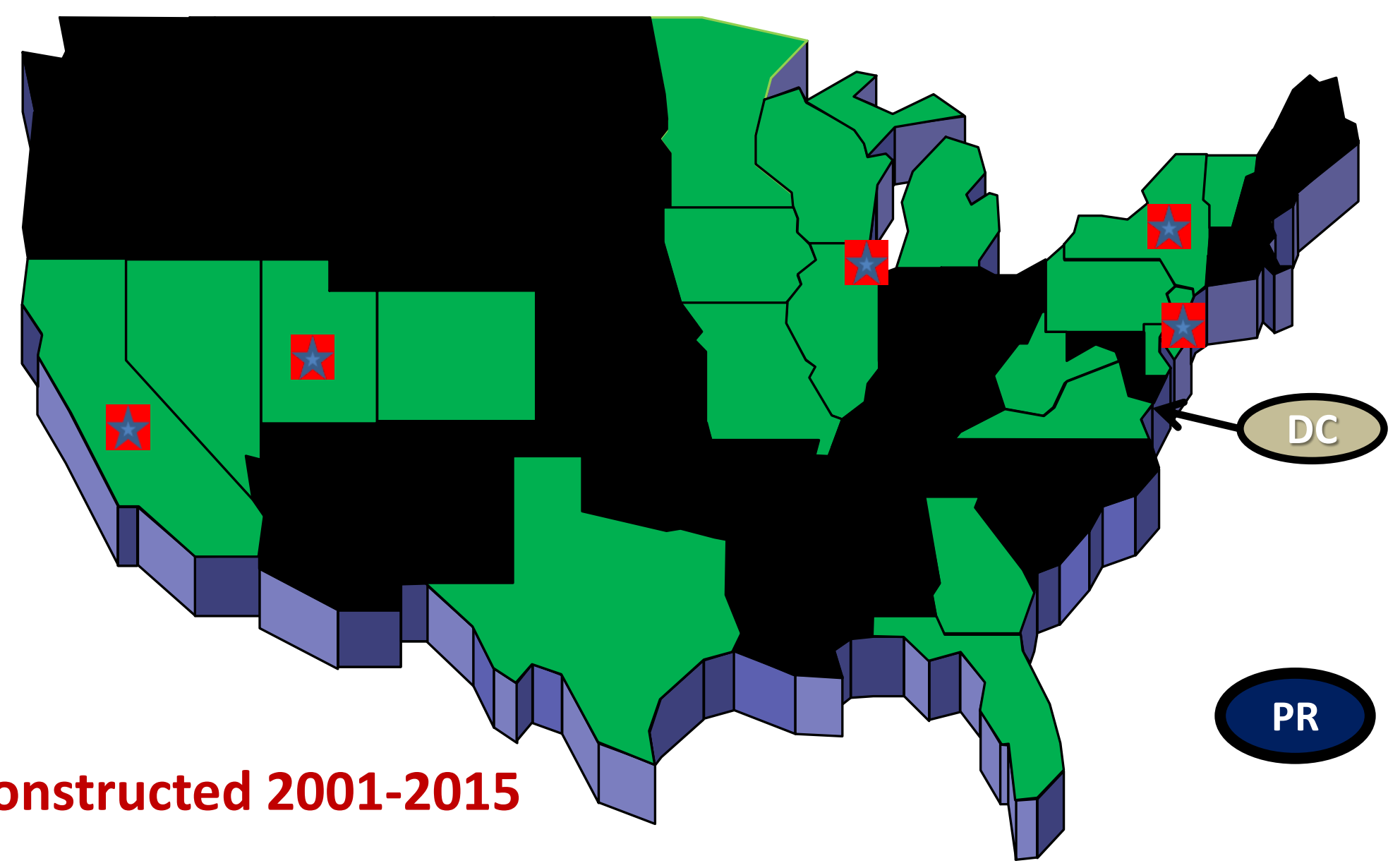

a PCP routinely used: CA, IL, NJ, NY (state, thruway \& city) \& UT 


\section{Highway Agencies Receiving SHRP2 PCP Implementation Awards in 2014 and 2015}
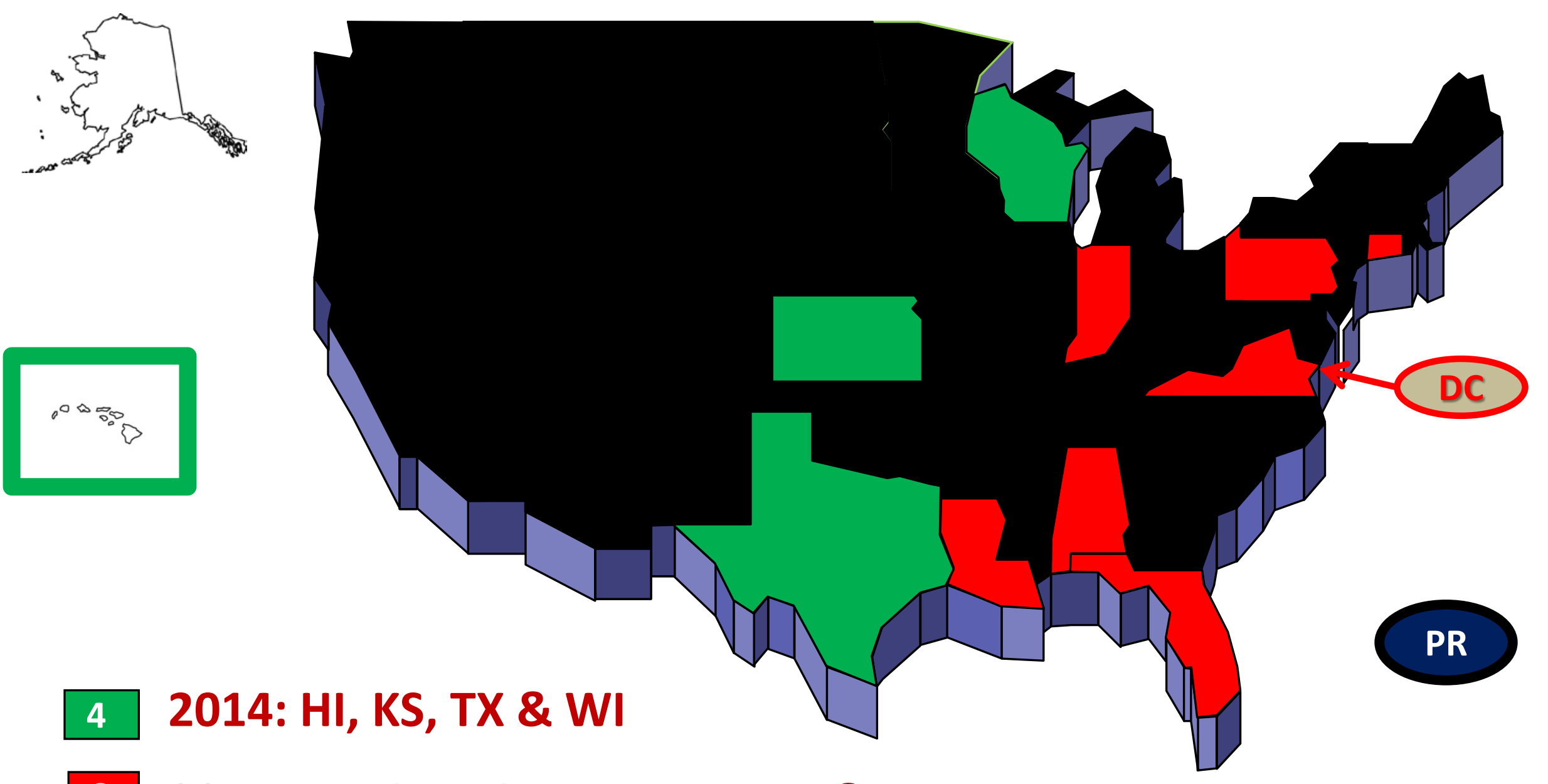

8 2015: AL, CT, DC, FL, IN, LA, PA \& VA 


\section{State of Practice - Jointed Systems}

\section{Overall Approaches}

\section{Support Condition}

1. Grade supported - panels are placed directly on grade

- Cemented bedding layer should be used (<1/2 in.)

- Surface grinding almost always required

2. Bedding grout supported - panels are set above grade using leveling bolts (or shims) and high strength bedding grout is used to fill gap under the panel (Typical gap $>1 / 4$ in $\&<1$ in.)

- Surface grinding may not be necessary

\section{Load Transfer System}

1. Using slots at the panel surface (several variations) 2. Using slots at the panel bottom (one patented system) 


\section{Panel Installation Options (Grade placed - Repair \& Continuous)}

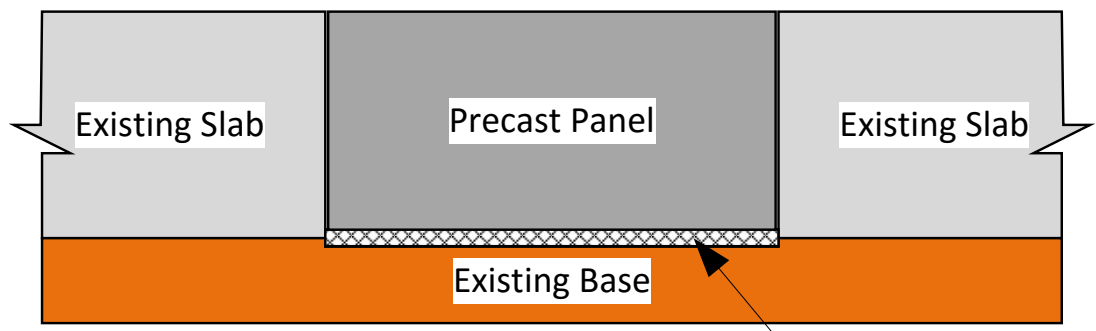

Prepared bedding (Granular or flowable concrete)

Or, cemented granular bedding, Or no bedding if base can be finished/graded well

Always undersealed

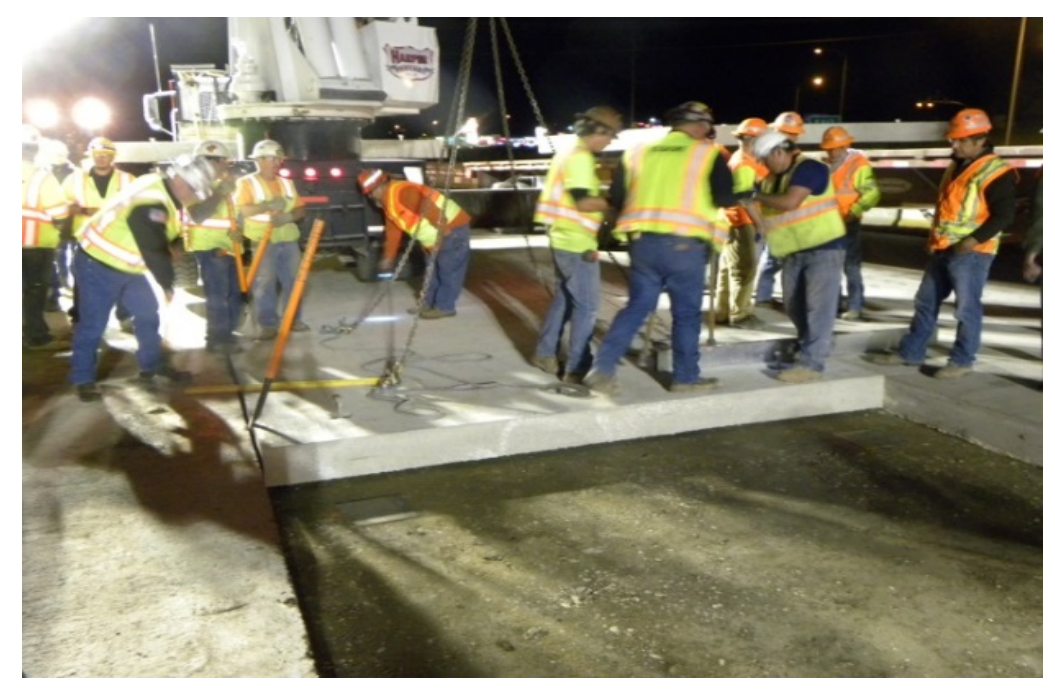




\section{Panel Installation Options (Levelling bolts $\mathcal{E}$ thicker bedding - Repair E continuous)}
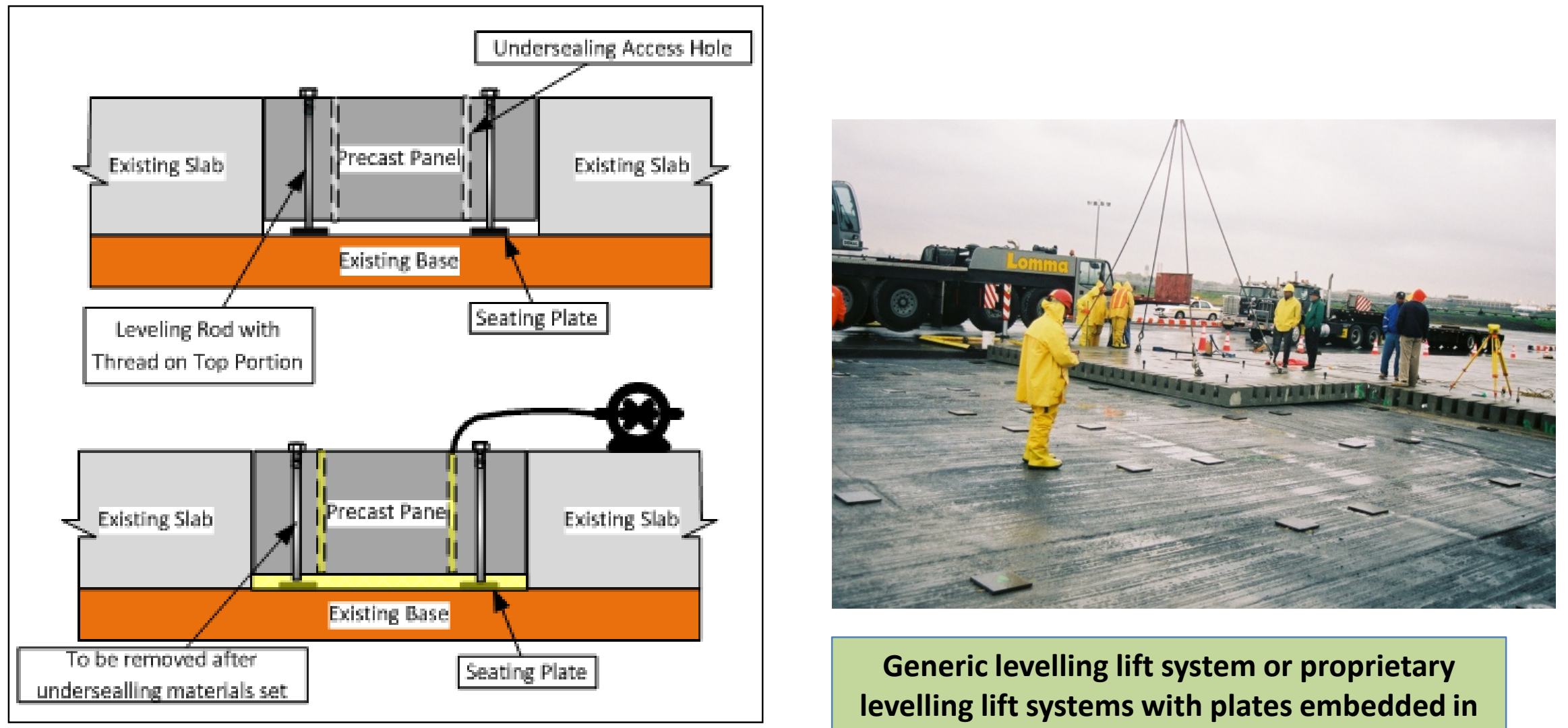

Generic levelling lift system or proprietary levelling lift systems with plates embedded in the panels (Gracie Lift, etc.) 


\section{Repair Panel Installation Options}

Roman Stone Method
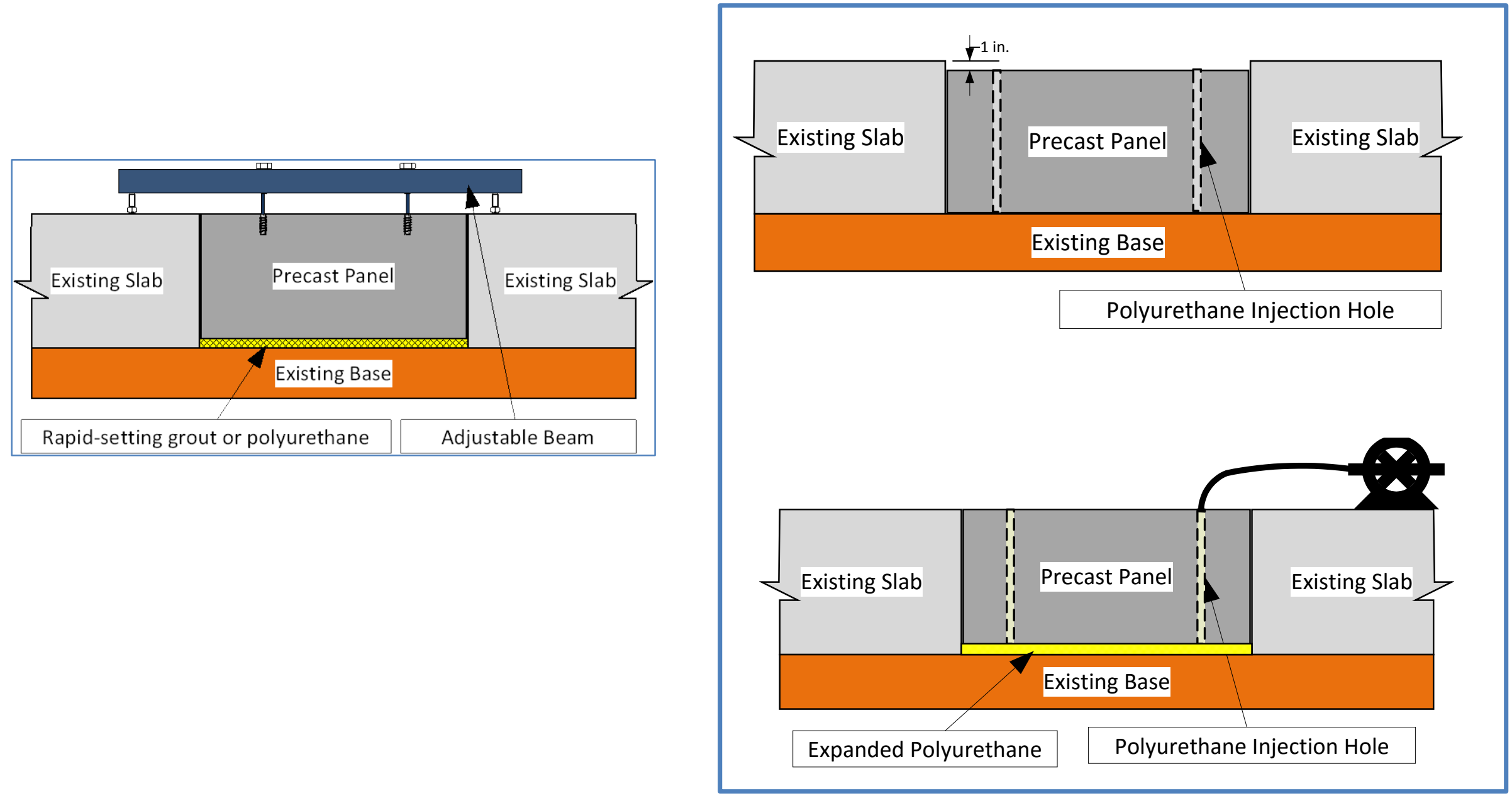


\section{PCP Load Transfer Alternatives}

- All systems require use of dowel bar slots

- Two approaches have been used

- The Fort Miller Super Slab bottom slots

- Generic top slots

- Michigan partial DBR approach - no longer used

- Full DBR approach - Eg., Roman Road system (New York)

- SHRP2 R05 narrow-mouth top slots (one sided or two-sided)

- Illinois Tollway version of narrow-mouth top slots (one-sided)

- California Barra Glide system - one-sided partial length narrow-mouth slots

- Caltrans version of narrow-mouth top slots (one sided) 


\section{PCP Load Transfer - Bottom Slots}

- Developed and patented by the Fort Miller Company (FMC)
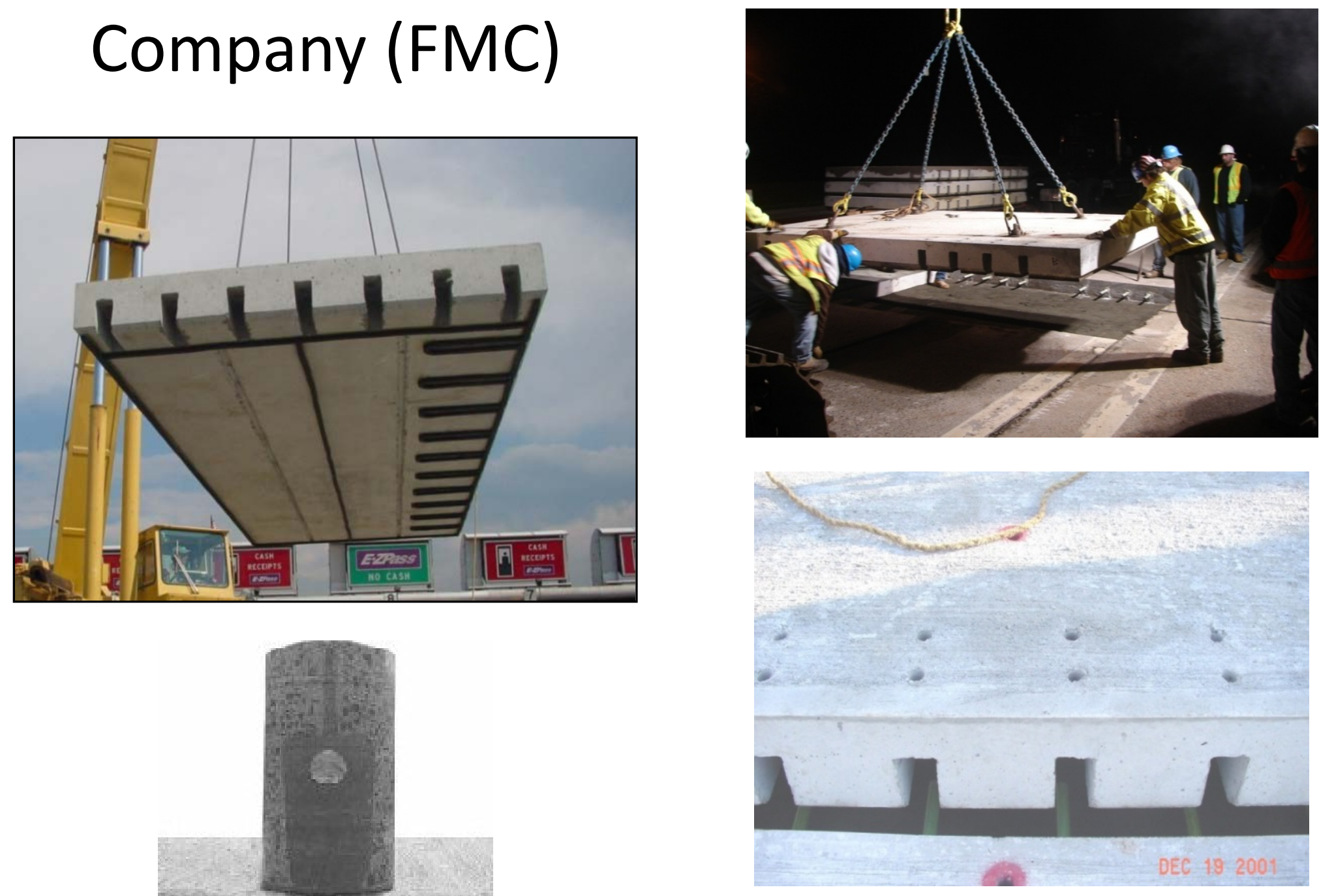


\section{PCP Load Transfer - Top Slots}

- Alternate method for installing dowel bars at transverse joints developed under the SHRP2 R05 project

- Using narrow dowel bar slots at the surface for transverse joint load transfer - allows opening to traffic before the dowel bar slots are patched
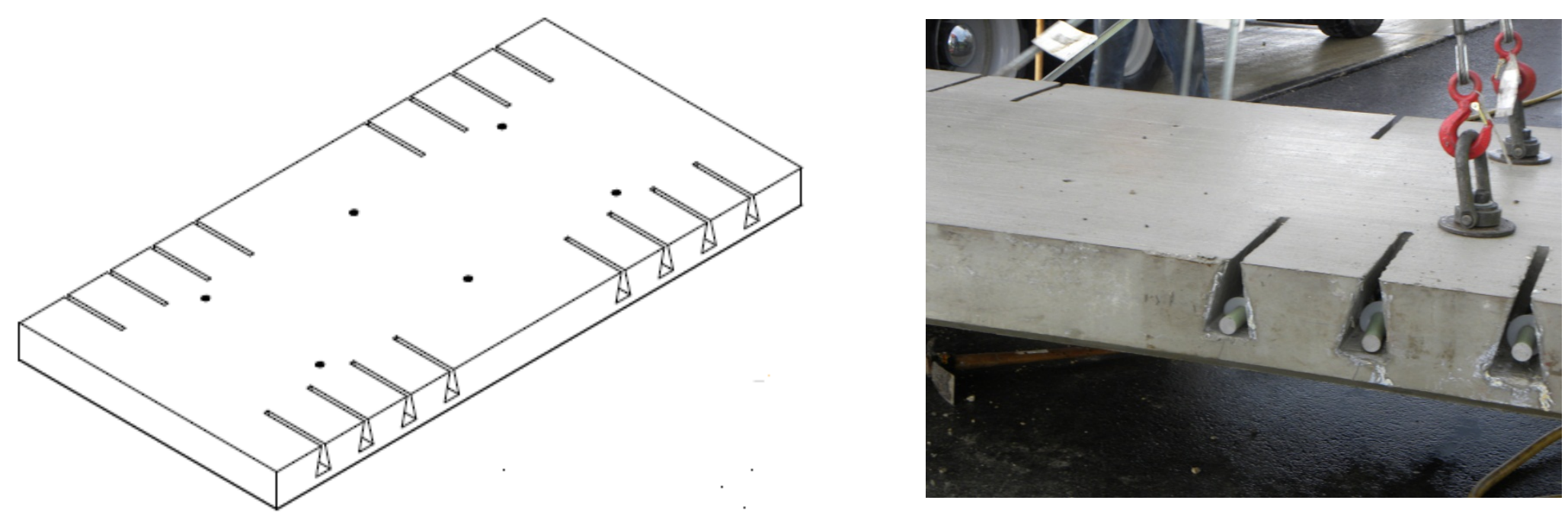


\section{PCP Load Transfer Refinement (USA)}

- Adopted by the Illinois Tollway

- Use of a narrow-mouth dowel bar slots at the surface

- Slots in panel for intermittent repairs

- Slots in every panel for continuous placement
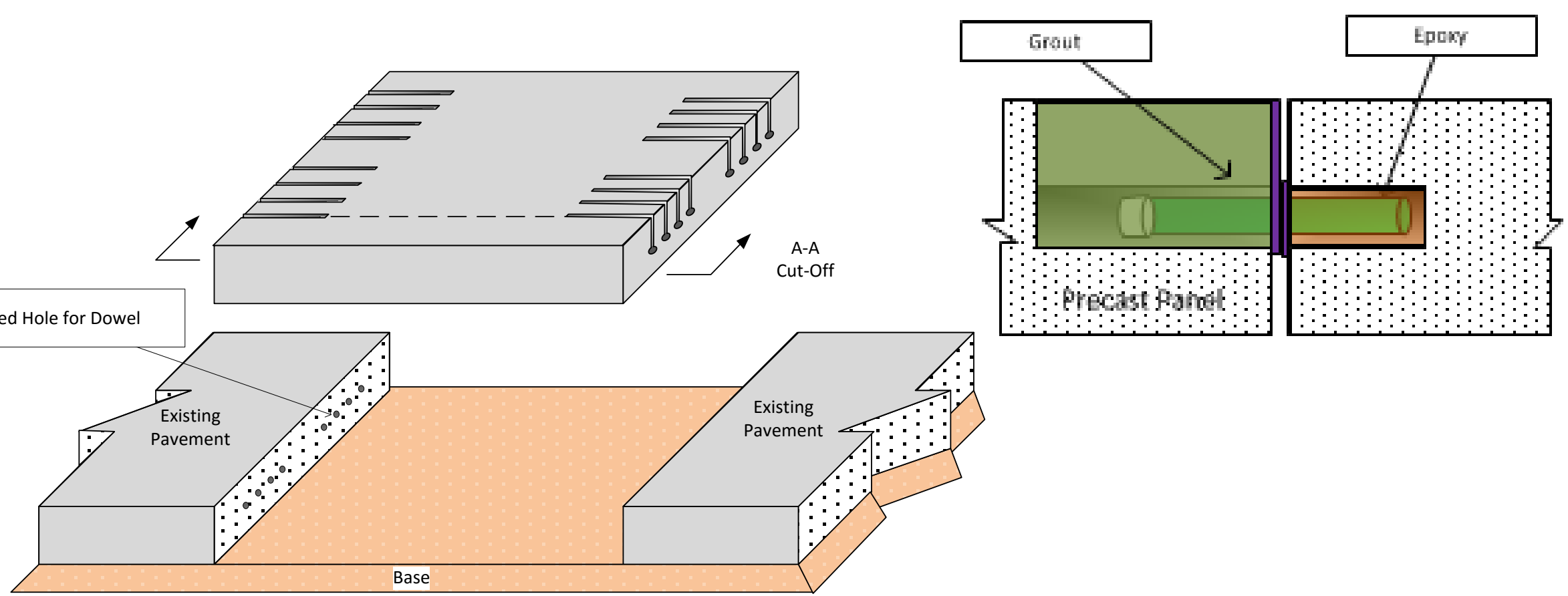


\section{California Rapid Roadway Pavement System}

\section{Barra Glide Load Transfer System E Gracie Lift Device Developed in 2013}
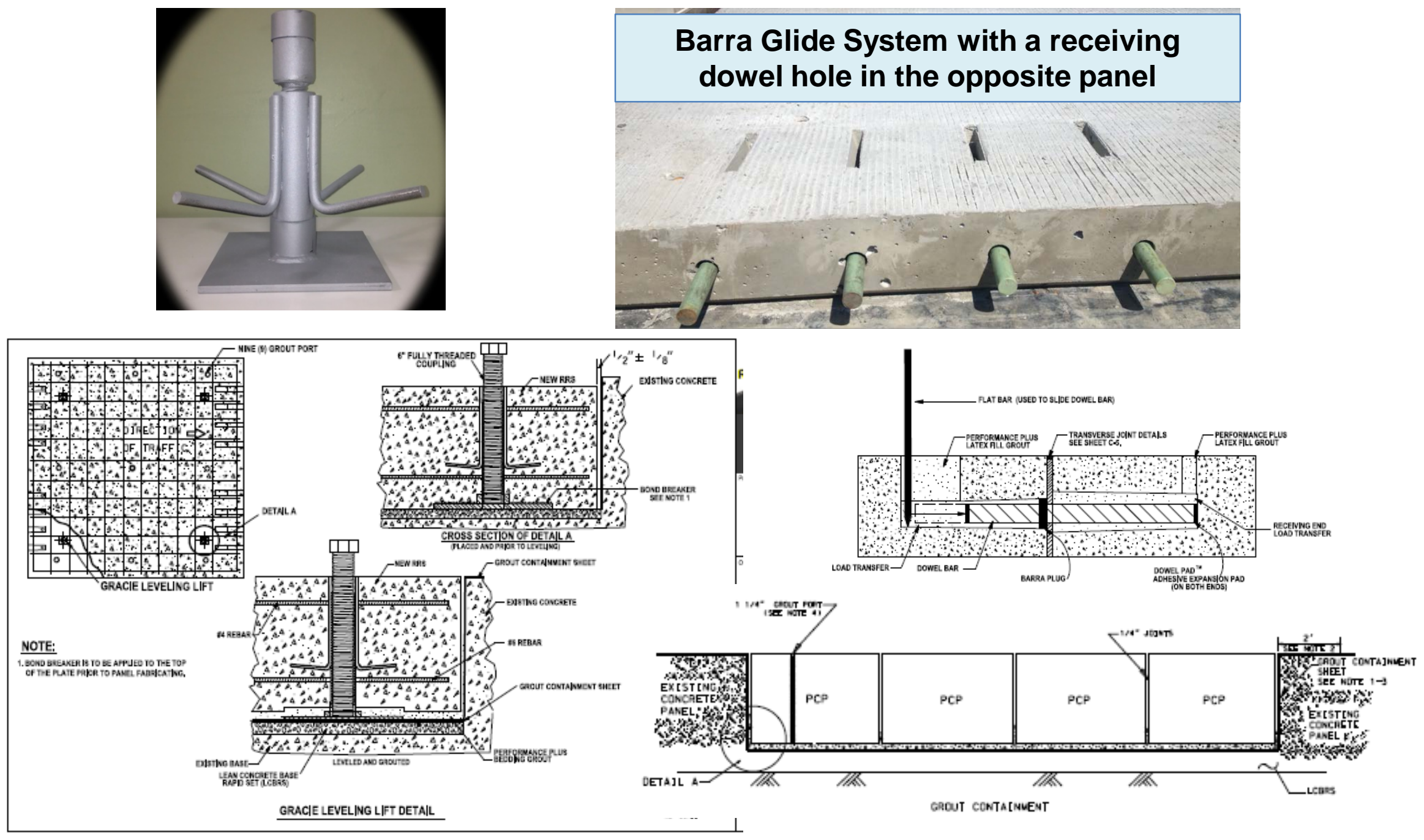


\section{California Rapid Roadway Pavement System}

Barra Glide Load Transfer System \& Gracie Lift Device
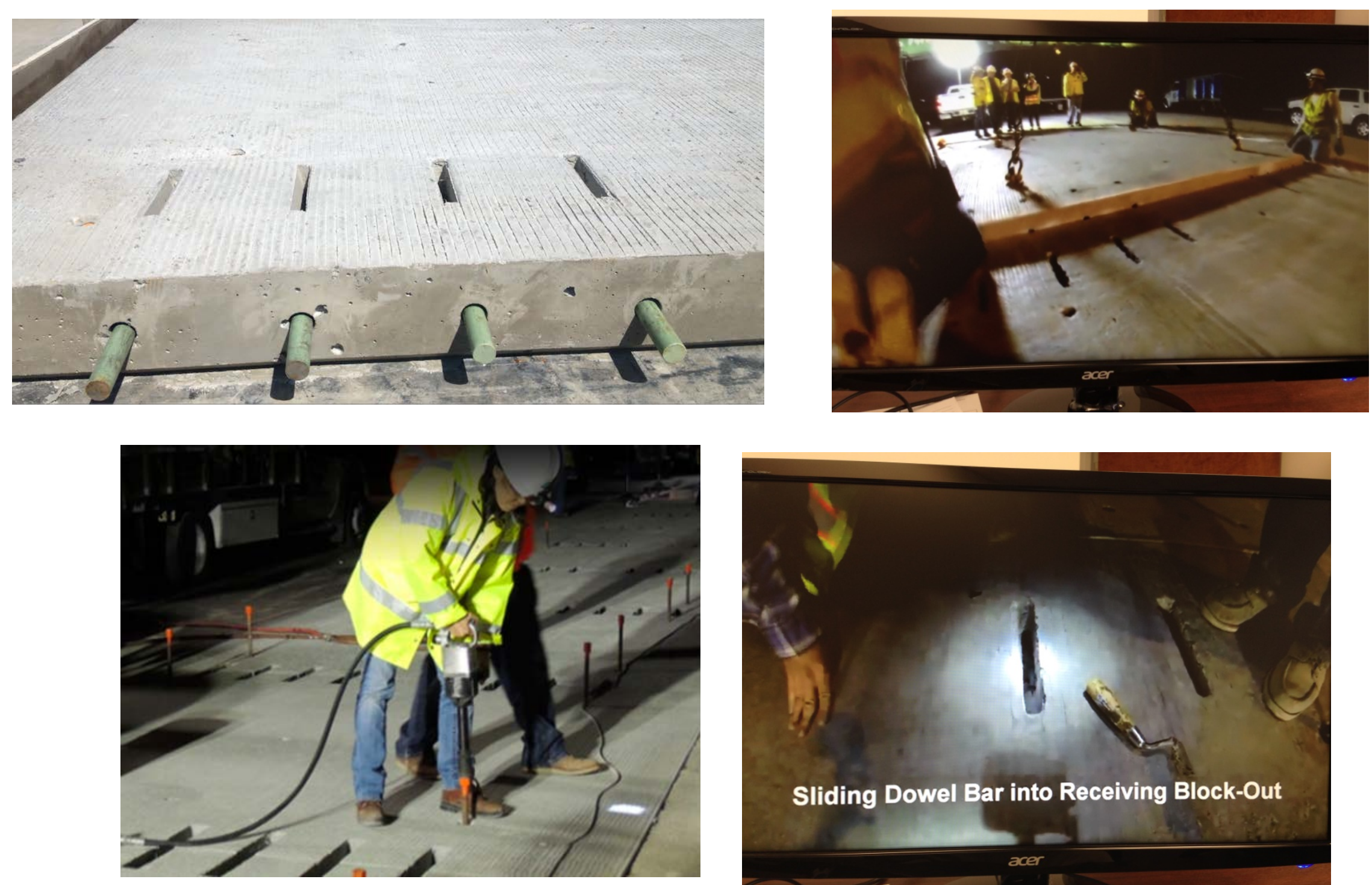

Sliding Dowel Bar into Receiving Block-Out 


\section{Caltrans Load Transfer Refinement}

Generic Caltrans Tear Drop Slot System used with Gracie Levelling Lift System (or Shims)
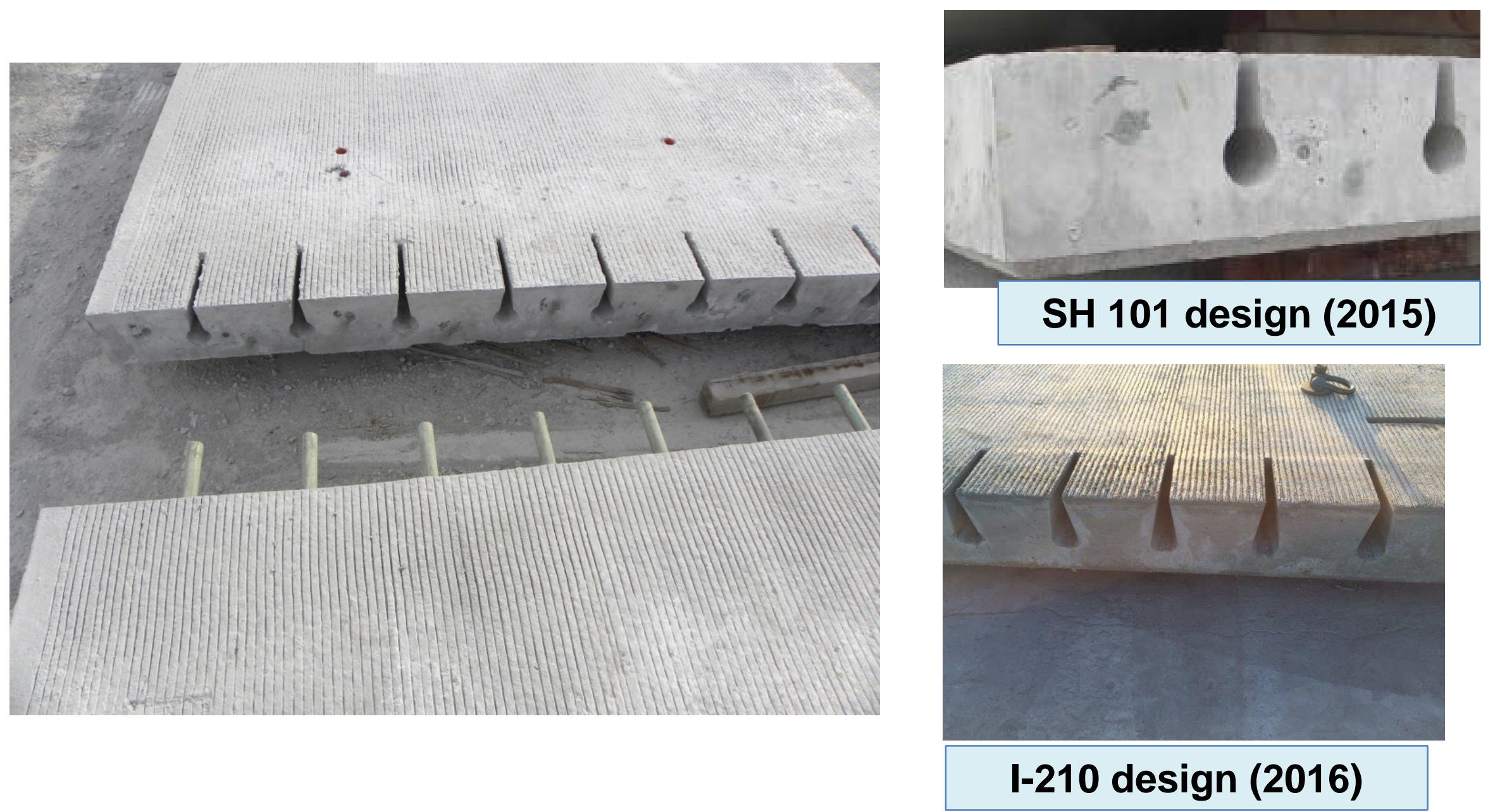


\section{PPCP Systems}

(Concept Developed at University of Texas - 2001)

- A number of panels are posttensioned together to result in a posttensioned section length of 200 to $250 \mathrm{ft} \&$ induced prestress of 150 to $200 \mathrm{psi}$

- Tendons are bonded to the concrete thru grouted tendon ducts
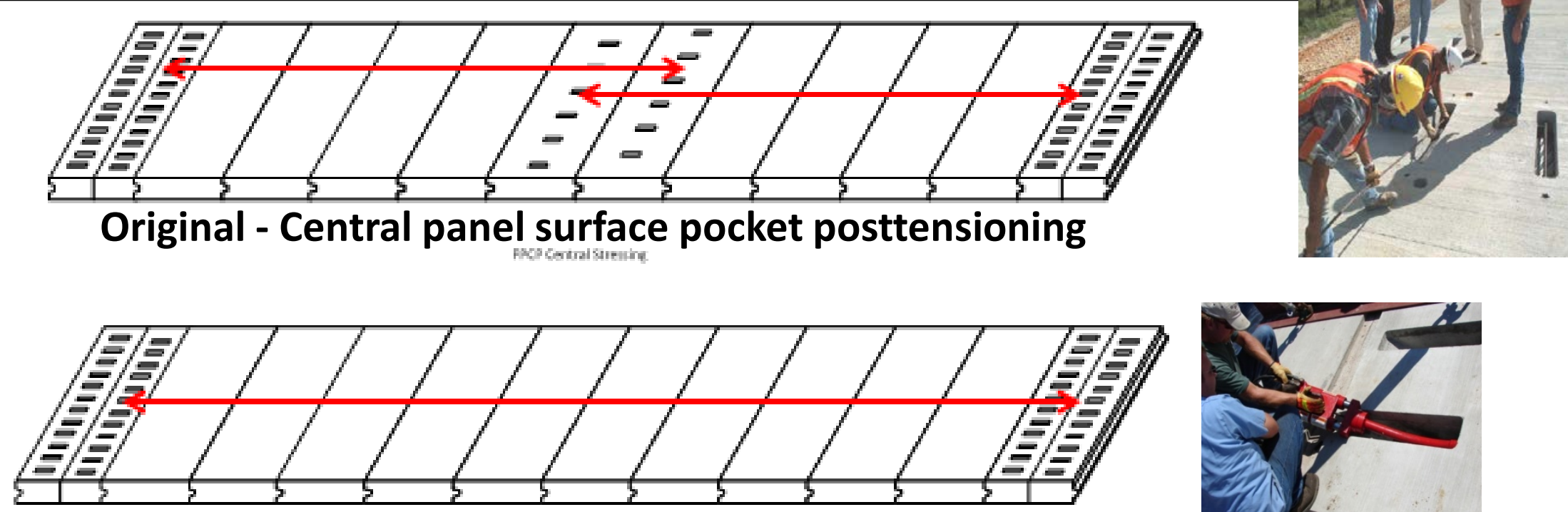

Refined - End panel surface pocket posttensioning
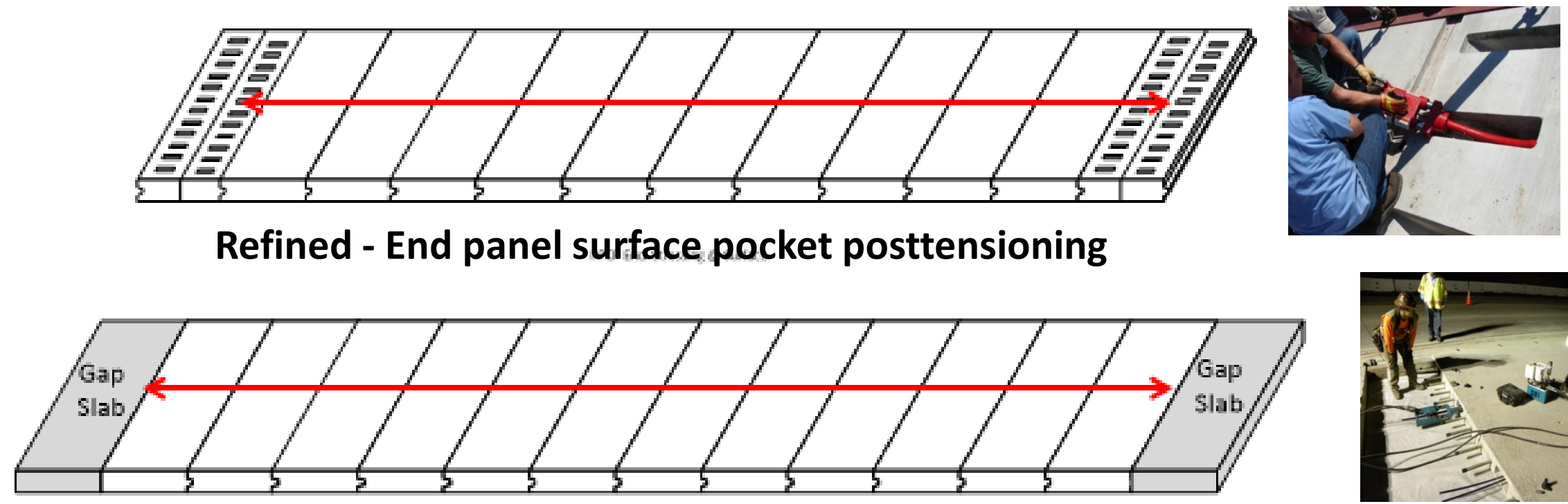

Current - End panel joint face posttensioning and gap panel use

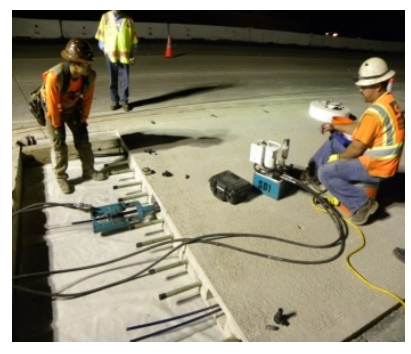




\section{Panel Production vs. Installation Rates}

- Panel fabrication rate

- 8 to 10 panels per day (inside plant - jointed)

- Similar rate for PPCP panels - inside plant or outdoor beds

- Panel installation rate

- Repair - 15 to 20 repairs/night

- Jointed continuous - 30 to 40 panels/night (500 to $600 \mathrm{ft})$

- PPCP - two posttensioned sections or up to about $500 \mathrm{ft}$

- So, several weeks (months) of back-log of panels is necessary before installation can begin

NEAR FUTURE EXPECTATIONS

REPAIR APPLICATION - 30 TO 40 REPAIRS PER NIGHT CONTINUOUS (JOINTED OR PPCP) - 1,000 + FT/NIGHT 
Where to Use Precast Pavement? (Open to Traffic the Next Morning!!!)

$>$ Primary Applications (90\%+ use)

- Heavily-traveled main line interstate/primary system \& urban roadways - A critical need on US's aging system

- Interstate/primary system \& urban ramps - Often no alternative routes and heavy traffic

$>$ Special Applications

- Intersections - Where traffic needs to be maintained

- Bridge approach slabs - A large no. of approach slabs across country need to be rehabilitated under traffic

- Underpasses - Where height restrictions may limit rehab options

- Bus pads - Where alternative bus stop locations are not acceptable, bus pads can be replaced overnight

- Airfield Applications - A developing market

- Utility "bridges" - Over failed drainage pipes \& culverts 


\section{Long-Life Expectations for PCP}

- Repair applications - 15 to 20 years or to reconstruction of existing pavement

- Continuous applications

- Original PCC surface service life - 40+ years

- Pavement will not exhibit premature failures and materials related distress

- Pavement failure=> Result of traffic loading

- Pavement will have reduced potential for cracking, faulting \& spalling, and

- Pavement will maintain desirable ride and surface texture characteristics with minimal intervention activities to correct for ride \& texture, for joint resealing, and minor repairs 


\section{PCP Technical Considerations}

a. General Details

b. Concrete Requirements

DIFFERENT SYSTEMS SHARE
MANY COMMON FEATURES AND
REQUIREMENTS

c. Jointing and Load Transfer

d. Support Conditions

BUT, THIS IS WHERE THEY DIFFER

e. Surface Characteristics (smoothness \& texture)

ONCE INSTALLED, PCPS BEHAVE SIMILAR TO CONVENTIONAL CONCRETE PAVEMENTS.

* Only the method of construction is different

THE CONCRETE \& THE PANELS CAN BE VERY DURABLE

However, uniform support condition \& good load transfer at joints are critical
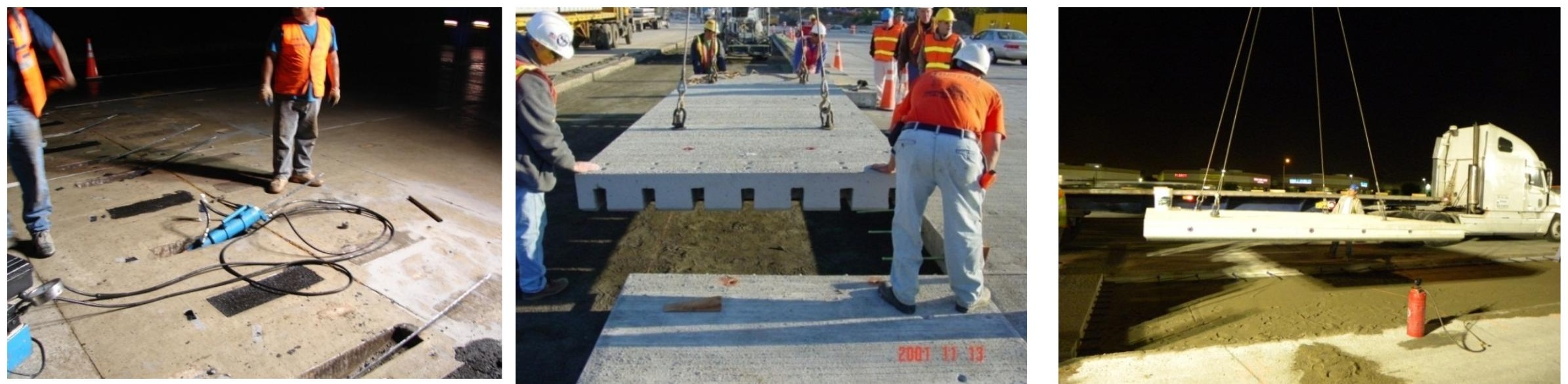


\section{Panel Static Lifting Flexural Stresses}

\begin{tabular}{|c|c|c|c|}
\hline $\begin{array}{l}\text { Panel Length } \\
\text { (ft.) }\end{array}$ & $\begin{array}{l}\text { Panel Width } \\
\text { (ft.) }\end{array}$ & $\begin{array}{c}\text { Panel } \\
\text { Thickness (in.) }\end{array}$ & $\begin{array}{l}\text { Maximum } \\
\text { Concrete Lifting } \\
\text { Stress (psi) }\end{array}$ \\
\hline \multirow{4}{*}{10} & 12 & 9 & 39 \\
\hline & 24 & 9 & 154 \\
\hline & 36 & 9 & 347 \\
\hline & 12 & 10 & 35 \\
\hline \multirow{3}{*}{$\begin{array}{l}\text { panel dimension gets } \\
r \text {, pretensioning } \\
\text { nes necessary }\end{array}$} & 12 & 11 & 32 \\
\hline & 12 & 12 & 29 \\
\hline & 12 & 9 & 39 \\
\hline \multirow{5}{*}{12} & 24 & 9 & 154 \\
\hline & 36 & 9 & 347 \\
\hline & 12 & 10 & 35 \\
\hline & 12 & 11 & 32 \\
\hline & 12 & 12 & 29 \\
\hline \multirow{6}{*}{15} & 12 & 9 & 60 \\
\hline & 24 & 9 & 154 \\
\hline & 36 & 9 & 347 \\
\hline & 12 & 10 & 54 \\
\hline & 12 & 11 & 49 \\
\hline & 12 & 12 & 45 \\
\hline
\end{tabular}




\section{Panel Fabrication (Current Jointed) - Reasonably Standard \& Routine}
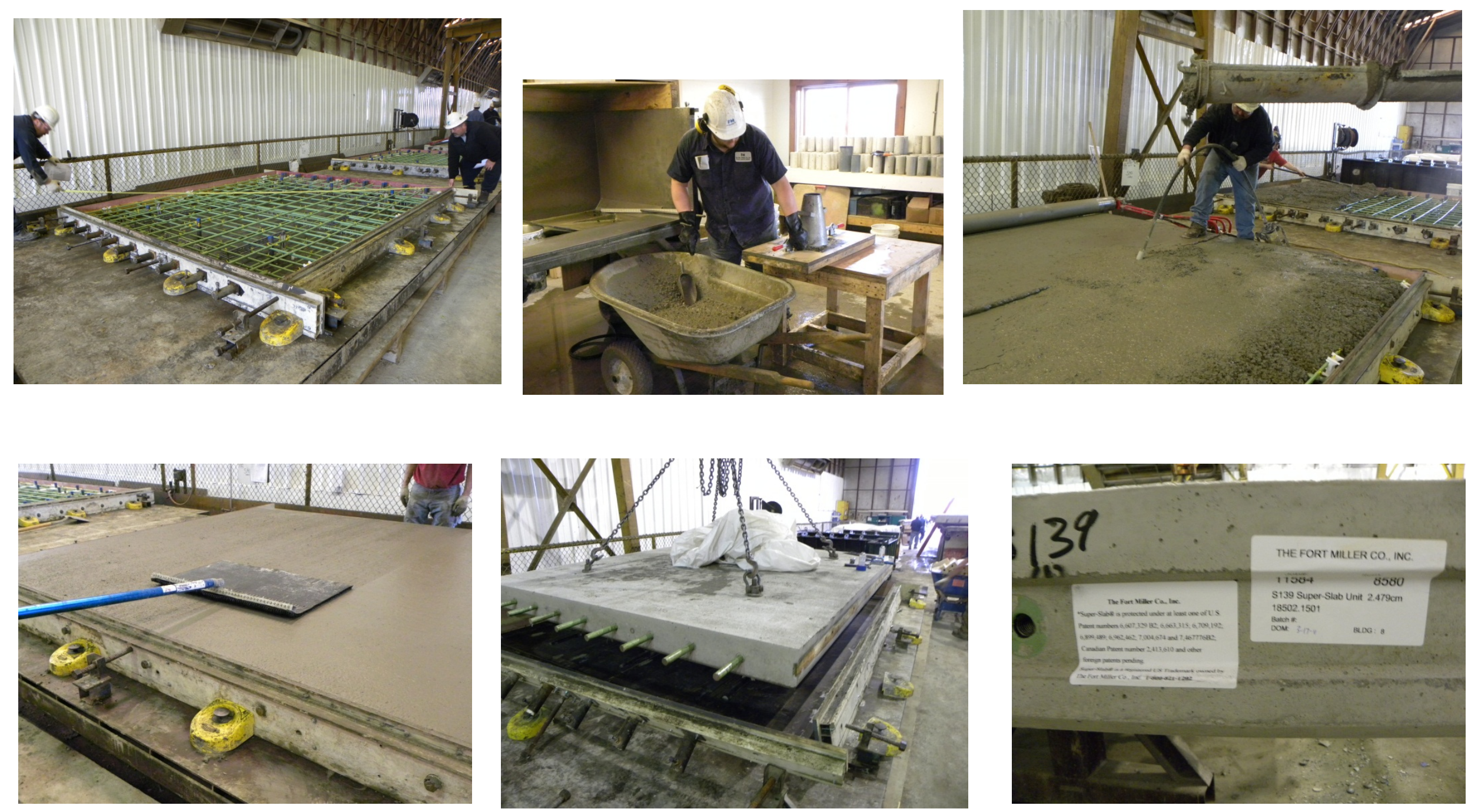


\section{The Panel Fabrication Process (Current) - Prestressed Panels for Jointed PCP}

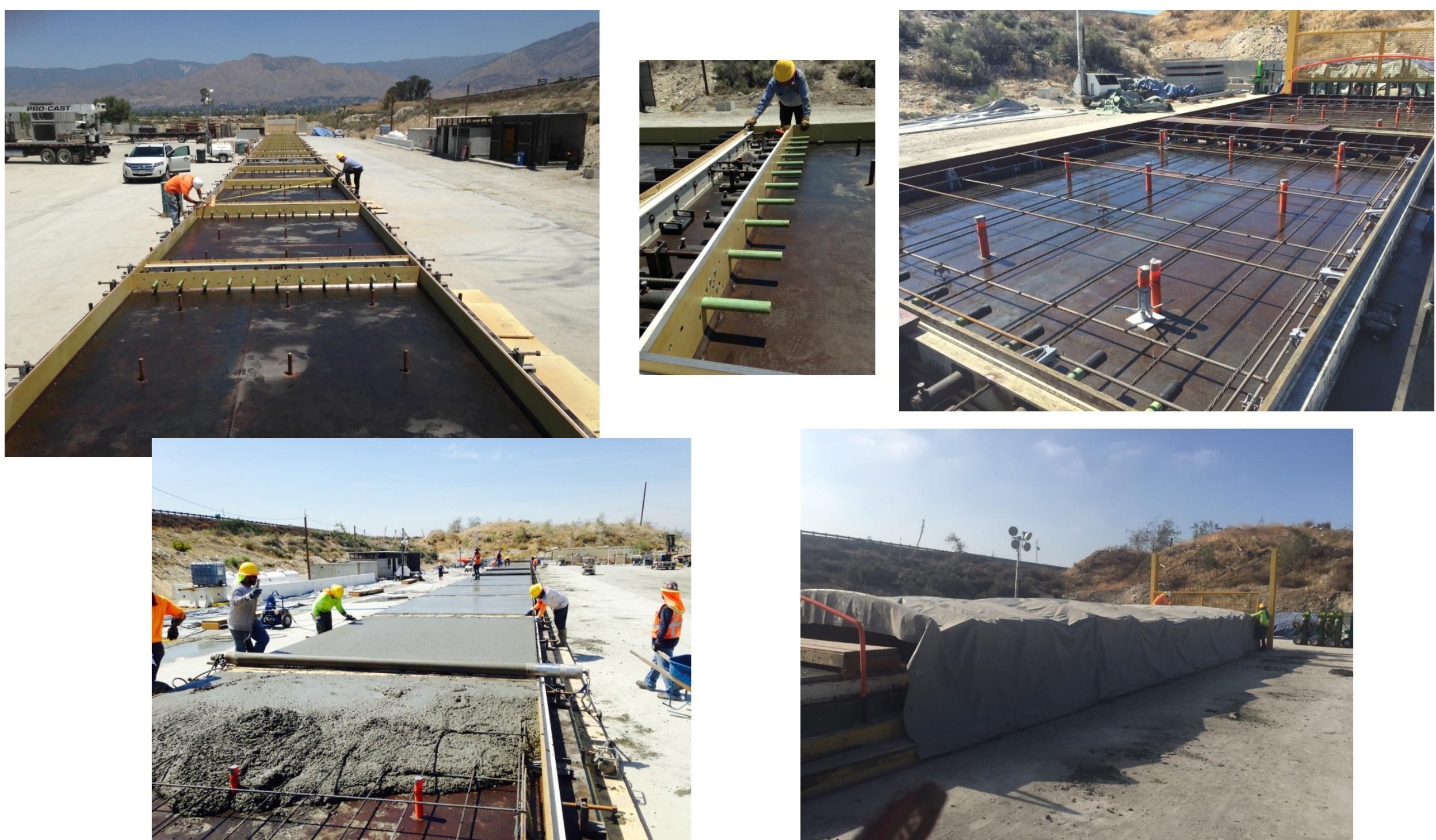




\section{Panel Support Condition Considerations}

- Use of existing base

- Granular

- Reworked, compacted \& regraded

- Reworked, compacted, regraded, bedding material applied

- Stabilized

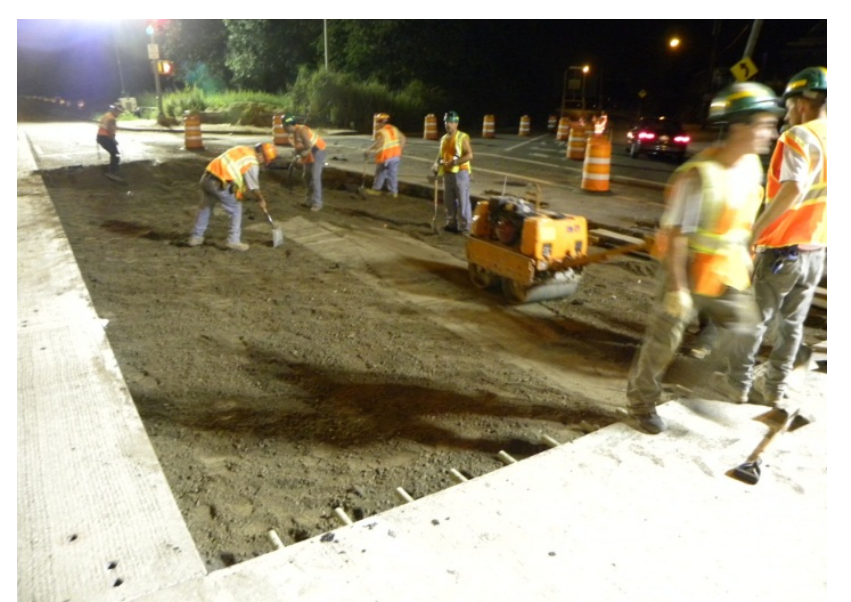

- Used as is or trimmed; bedding material applied

- Bedding material

- $<1 / 4$ in. fine-grained granular material

- Thicker layer of rapid-setting flowable fill (RSFF) or grout using elevated panel placement techniques (levelling bolts/shims)

- High density polyurethane grout

- New base - granular or rapid-setting LCB, with or without bedding material 


\section{PCP Overview Summary}

$>$ Although experience with PCP systems is limited, less than 15 years, performance to-date indicate that well-designed and well-constructed PCP systems can be installed rapidly and can be expected to provide long-term service

$>$ There were some early teething problems, but we are well beyond those issues

$>$ The need for the technology is obvious - rapid construction and longer-lasting solutions.

$>$ Several generic and proprietary PCP systems are available

$>$ And, importantly, contractors with no prior PCP construction experience are successfully installing precast panels 
